\title{
Chewable-Dispersible Tablet Dosage Form
}

National Cancer Institute

\section{Source}

National Cancer Institute. Chewable-Dispersible Tablet Dosage Form. NCI Thesaurus.

Code C149369.

An uncoated tablet intended either to be chewed before being swallowed, or to be dispersed in the specified liquid before being swallowed. 